\title{
Negative Regulation of G2 Phase
}

National Cancer Institute

\section{Source}

National Cancer Institute. Negative Regulation of G2 Phase. NCI Thesaurus. Code C40775.

G2 Phase Arrest consists of interference with, or restraint of, activities that regulate the cellular capacity to transit the cell cycle phase preceding mitosis (Gap 2 phase). The chromosomes are tetraploid in this phase. 